\title{
ON THE CAUCHY-BUNIAKOWSKY-SCHWARTZ'S INEQUALITY FOR SEQUENCES IN INNER PRODUCT SPACES
}

\author{
S. S. DRAGOMIR
}

Abstract. In this paper we consider some mappings naturally connected to Cauchy-BuniakowskySchwartz's inequality for sequences of vectors in inner product spaces and point out their main properties. Some applications are also given.

Mathematics subject classification (1991): 26D20, 46 C05.

Keywords and phrases: Inequalities, Schwartz inequality in inner product spaces, Cauchy-BuchiakowskySchwartz's inequality.

\section{REFERENCES}

[1] S. S. Dragomir, Some refinements of Schwarz's inequality, Proc. Symp. Math. and its Appl., Nov. 1985, Pol. Iust. Timisoara, p. 13-16. ZBL No. 594:46018.

[2] S. S. DrAGOMIR AND J. SÁNDOR, Some inequalities in prehilbertian spaces, Studia Univ. "Babes-Bolyai"'Mathematica, 32(1) (1987), p. 71-78. MR 89h: 46034.

[3] S. S. DRAGOMIR AND N. M. IONESCU, A refinement of Grüss' inequality in inner product spaces, Proc. Fourth. Symp. Math. and its Appl., 1-2 Nov. 1991, Pol. Inst. Timisoara, p. 188-191.

[4] S. S. DRAGOMIR AND J. E. PEČARIČ, On Cauchy-Buniakowsky-Schwartz's inequality in Banach spaces, Proc. Fifth. Symp. Math. and its Appl., 29-30 Oct. 1993, Techn. Univ. Timisoara, 1993, p. 93-98.

[5] S. S. DRAGOMIR AND B. MOND, On the superadditivity and monotonicity of Schwarz's inequality in inner product spaces, Acta Math. Hung., 70(1996), 129-143.

[6] S. S. DRAGOMIR AND B. MOND, Some new inequalities for Gram determinants in inner product spaces, Univ. Beograd Publ. Elek. Fak., Math., 6(1995), 38-45.

[7] S. S. DRAGOMIR AND B. Mond, Some mappings associated with Cauchy-Buniakowski-Schwarz's inequality in inner product spaces, Soochow J. of Math., 21(4)(1995), 413-426.

[8] S. S. DRAGOMIR AND B. Mond, Some inequalities for Fourier coefficients in inner product spaces, Periodica Math. Hungarica, 32(3)(1995), 413-426.

[9] S. S. DRAGOMIR AND B. MOND, On the superadditivity and monotonicity of Gram's inequality and related results, Acta Math. Hungarica, 71(1-2)(1996), 75-90.

[10] S. S. DRAGOMIR, B. Mond AND Z. PALES, On a superadditivity property of Gram's determinant, Aequationes Matematicae, 54(1997), 199-204.

[11] S. KUREPA, Note on inequalities associated with Hermitian functionals, Glasnik Mat., 3(23)(1968), p. 197-206.

[12] F. T. MetCALF, A Bessel-Schwarz inequality for Gaussians and related bounds for determinants, Ann. Math. Pura. Appl., 4, 68(1965), p. 201-232.

[13] D. S. Mitrinović, J. E. PeČARIĆ AND A. M. Fink, Classical and New Inequalities in Analysis, Kluwer Academic Publishers, Dordricht/Boston/London, 1993. 